\section{Effect of positive feedback on compliance following transgression}

\author{
DAVID L. MCMILLEN and JAMES B. AUSTIN \\ Mississippi State University, State College, Miss. 39762
}

The hypothesis was tested that positive feedback following transgression would lead to less compliance than would an absence of feedback following transgression. It was also predicted that compliance following transgression would be reduced if a high self-esteem manipulation preceded the compliance request. A 2 by 2 by 2 factorial design manipulating transgression, self esteem, and feedback was employed. Results supported the hypothesis.

Numerous studies have indicated that compliant behavior increases following transgression (Brock \& Becker, 1966; Freedman, Wallington, \& Bless, 1967; Carlsmith \& Gross, 1969; McMillen, 1970, 1971). A "guilt", interpretation has been suggested by some investigators (e.g., Freedman et al, Carlsmith \& Gross) to account for the findings. Brock (1969) proposed the "fate control" interpretation. This interpretation viewed compliance as a means of maintaining fate control over $\mathrm{E}$, which $S$ had established as a result of transgression.

An additional explanation suggested by Carlsmith \& Gross (1969) and McMillen (1970) focused on the importance of compliant behavior as a means of bolstering one's selfesteem following transgression. According to this interpretation, the act of transgression functions to lower selfesteem and the act of compliance serves to restore self-esteem. This explanation is based on the assumption suggested by Aronson (1969) that if an individual's behavior is inconsistent with his self-concept, dissonance will be aroused. In most transgression-compliance experiments, the $\mathrm{S}$ has been faced with a cognition concerning his dishonesty (e.g., "I cheated") or a cognition concerning his incompetence (e.g., "I damaged the machine"). Such a cognition should arouse dissonance for people who possess a positive self-image.

The "self-esteem" interpretation received indirect support from Carlsmith and Gross's finding that greater compliance occurred when the request was made by a witness than when the request was made by the victim of the transgression. McMillen (1971) offered direct support for the "self-esteem" interpretation. Half of his Ss received a manipulation designed to raise their self-esteem. This manipulation occurred following transgression but prior to the compliance request. Differences in compliance between transgression and no-transgression Ss occurred only when Ss received no selfesteem manipulation. This finding seems to indicate that compliant behavior can serve to compensate for a reduction in self-esteem which occurs as a consequence of transgression. The finding also suggests that if other means are available to compensate for lost self-esteem, compliance is not as likely to occur. It can be hypothesized that when transgression produces a positive outcome for the transgressor, he receives compensation for his loss in self-esteem and dissonance does not occur. The present study was designed to test this hypothesis. It was predicted that compliant behavior would be significantly reduced by supplying Ss with a reward which resulted from their transgression. The experiment consisted of a 2 by 2 by 2 factorial design. Half of the $\mathrm{Ss}$ were given an opportunity to cheat on a test; the other half were not. Half the Ss were given positive feedback concerning their test performance; the other half were given no feedback. Half the Ss were given information designed to bolster their self-image; the other half were given no information.

The Ss were 80 male introductory psychology students at Mississippi State University. They participated as partial fulfillment of course requirements. Ten Ss were assigned randomly to each of eight groups. Ss were scheduled in pairs, each $S$ being paired with a student in a class other than his own. When they arrived, they were seated in a waiting room and told that the previous Ss had not completed the experiment as yet. $E$ left the room; $1 \mathrm{~min}$ later the confederate entered, saying that he was looking for a book he had forgotten when he was in an experiment earlier in the day. The confederate engaged $S s$ in a brief informal discussion. During the course of this discussion, the confederate furnished the half of Ss with information about the experiment. Specifically, he said that he had taken a multiple-choice psychology test. He further stated that after he had completed the test, $\mathrm{E}$ had shown him the answer key and he had been surprised to learn that the majority of the correct answers were "B." In the control condition, the confederate did not discuss the experiment. If $S$ asked about the experiment, the confederate claimed that he had been in a person-perception experiment.

The confederate's decision to administer the experimental manipulation was determined by a coin flip prior to entering the waiting room. E was not made aware of the confederate's decision until the experiment had been completed. Four or $5 \mathrm{~min}$ after he entered the waiting room, the confederate exited. A few minutes later, $E$ returned and began to explain the purpose of the experiment. The following preliminary instructions were given to all Ss:

"Have either of you been in this experiment before or heard anything about it? [None of the Ss admitted knowing anything about the experiment.]

"As you probably know, the University is presently engaged in a large-scale self-study and self-improvement program. In this department we are trying to assess the effectiveness of our courses in meeting student needs. The course most frequently criticized both by students and instructors is introductory psychology. There are several changes we are considering for the course; however, before making major changes, we need to determine the extent to which the average student is knowledgeable in the field of psychology. In this experiment we are administering diagnostic psychology tests to a large number of students in an attempt to find out how much psychology students know before taking the introductory course. ${ }^{2}$ The test which you will take is a 50-question multiple-choice test. I want you to take your time and read each question carefully before you mark an answer. Remember, it is important that we get a true picture of your knowledge of psychology. This test will not affect your course grade unless you make a high score. If that occurs, I have made arrangements with your instructors, Dr. Hudson and Mr. Mapp, for you to receive credit for this test in your course grade. If your score is fair or poor it will not affect your grade. Do you have any questions?"

At this time, Ss were taken to separate cubicles to complete their tests. They were observed through a one-way mirror to determine when they had completed the test. At this point, the second confederate entered 
Table 1

Mean Amount of Compliance in Minutes

\begin{tabular}{|c|c|c|c|c|}
\hline & \multicolumn{2}{|c|}{ Self-Esteem } & \multicolumn{2}{|c|}{ No Self-Esteem } \\
\hline & $\begin{array}{l}\text { Infor- } \\
\text { mation }\end{array}$ & $\begin{array}{l}\text { No Infor- } \\
\text { mation }\end{array}$ & $\begin{array}{l}\text { Infor- } \\
\text { mation }\end{array}$ & $\begin{array}{c}\text { No Infor } \\
\text { mation }\end{array}$ \\
\hline $\begin{array}{l}\text { Positive Feedback } \\
\text { No Feedback }\end{array}$ & $\begin{array}{l}11.0 \\
29.5\end{array}$ & $\begin{array}{r}35.0 \\
6.5\end{array}$ & $\begin{array}{l}18.0 \\
63.0\end{array}$ & $\begin{array}{r}40.5 \\
1.5\end{array}$ \\
\hline
\end{tabular}

the cubicle. The second confederate was the same person who administered a personality test to all students on the first day of class. ${ }^{3}$ Before entering the cubicle, the confederate flipped a coin to determine whether or not he would administer the self-esteem manipulation to that particular $S$. If the $\mathbf{S}$ was to receive no manipulation, the confederate entered the cubicle and picked up a folder of papers from a table on the opposite side of the cubicle from the $S$. The confederate apologized for the interruption and retired from the cubicle.

For those Ss selected to receive the self-esteem manipulation, the actions of the confederate were the same. In addition, he asked the $S$ if he was taking introductory psychology. When the $S$ responded in the affirmative, the confederate asked for the S's name and said, "I have the results of the personality test you took the other day. I am mailing them, but I'll give yours to you now." He sorted through the folder of papers and handed the $S$ a sheet of paper with the results of his personality test on it. Actually, these test results were bogus and were the same for all Ss recelving a manipulation. The sheet of paper had the S's name at the top. It listed five subscales of test (capacity for status, sociability, social presence, self-acceptance, plus the total), and check marks indicated whether the $\mathrm{S}$ scored high, medium, or low on each scale. There was also a short handwritten interpretation signed by a fictitious Dr. Arthur Hill. In'all cases, the $S$ received high ratings on the total and four of the five subscales; he received a medium rating on the remaining subscale. The scale which had the medium rating was randomly alternated. The written interpretation was as follows for all Ss:

"Subject shows self-assurance and some self-reliant trends. His thinking and approach toward interpersonal relationships is primarily resourceful and flexible in nature. His CPI profile suggests poise in unfamiliar social situations and a corresponding genuine acceptance from his peers."

The confederate told $S$ he would be available after the experiment to answer any questions about the personality test.

About $2 \mathrm{~min}$ after the second confederate left the cubicle, E returned and collected S's test and answer sheet. E told half the Ss, "You will be notified of your test score in a few days." For the other Ss, E took out a grading key and pretended to score S's test. He then told S, "You did quite well on the test. I will inform your instructor of your grade, and he will count it as one lecture quiz." (E determined if he would give $S$ high feedback or not by flipping a coin prior to entering the cubicle.)

The $E$ informed the $S$ that the experiment was concluded. In addition, E said: "You are free to leave. However, if you have some spare time, I could use your help in scoring some questionnaires [ $E$ pointed to the adjacent table where there was a stack of about 500 answer sheets and a scoring key.] This is not a part of the experiment, and you don't have to do it. But I could use your help if you have the time."

The amount of time the $S$ agreed to help was the measure of compliant behavior. The $S$ did not actually do any work. When he had made his decision and specified the amount of time he would work, the purpose of the experiment was fully explained. $S$ was asked not to talk about the experiment to anyone and was dismissed.

\section{Results and Discussion}

The mean of 15.0 " $B$ " responses for the Ss with information was significantly different from the mean of 11.0 for the Ss without information $(F=23.9$, df $=1,72, p<.01)$. This finding indicates that $S$ s wo had information and denied they had it did make use of that information. There were no significant differences in the number of " $B$ " responses among the four groups with information, nor were there any significant differences among the four groups without information.

Table 1 indicates the mean amount of compliance in minutes for the various treatment groups. The Information by Feedback interaction was highly significant $(F=45.23$, $\mathrm{df}=1,72, \mathrm{p}<.001$ ). This supports the basic prediction of the study. In the no-feedback conditions, compliance is greater following transgression; however, in the positive-feedback conditions, less compliance occurs in the transgression groups than in the no-transgression groups. It seems likely that when a positive outcome results from an act of transgression, it offsets any loss of self-esteem which the act of transgressing may have caused. If so, there would be a reduced need to comply to restore self esteem.

There are several possible explanations for the relatively high degree of compliance by $S s$ in the no-information/positive-feedback groups. It could be that because $E$ had furnished a positive outcome, he was liked and Ss were willing to help him. It is also possible that no-information/positive-feedback Ss complied because they felt they owed E something for the positive outcome they had received or because they were afraid $E$ would renege on the positive outcome if they did not comply.

None of the interpretations would apply to Ss in the information/ positive-feedback groups if, as Carlsmith \& Gross's (1969) and McMillen's (1971) data indicated, Ss who transgress will avoid contact with their victim when other means are available to restore self-esteem.

There is a significant Information by Self-Esteem interaction $(F=4.22$, df $=1,72, \quad p<.05$ ). When a high self-esteem manipulation is administered following transgression but prior to the compliance request, less compliance occurs than when no manipulation is given. This result replicates an earlier finding by McMillen (1971) and supports the hypothesis that compliance serves to restore self-esteem which was lost as a consequence of transgression.

\section{REFERENCES}

ARONSON, E. Dissonance theory: Progress and problems. In R. Abelson, E. Aronson, W. McGuire, T. Newcomb, M. Rosenberg, and $P$. Tannenbaum (Eds.), Theories of cognitive consistency: $A$ sourcebook. Chicago: Rand McNally, 1969.

BROCK, T.C. On interpreting the effects of transgression upon compliance. Psychological Bulletin, 1969, 72 , 138-145.

BROCK, T. C., \& BECKER, L. A. "Debriefing", and susceptibility to subsequent experimental manipulations. Journal of Experimental Social Psychology, 1966, 2, 314-323.

CARLSMITH, J. M., \& GROSS, A. E. Some effects of guilt on compliance. Journal of Personality \& Social Psychology, 1969, 11. 240-244.

FREEDMAN, J. L., WALLINGTON, S. A., \& BLESS. E. Compliance without pressure: The effect of guilt. Journal of Personality \& Social Psychology, 1967, 7, 117-124.

McMILLEN, D. L. Transgression, fate control, and compliant behavior. Psychonomic Science, 1970,21, 103-104.

McMILLEN, D. L. Transgression, self-image and compliant behavior. Journal of Personality \& Social Psychology, in press. NOTES

1. Actually, Answer B was correct for 10 of the 50 questions. During the course of debriefing, $E$ questioned $S$ to determine if he had been, for any reason, suspicious of the confederate. None of the Ss stated they were suspicious. 
2. All Ss were run during the second and third day of classes, and the test questions were on topics usually covered during the last half of the course. In all cases this was the first psychological experiment the $S$ had participated in.

3. The test he had administered was the Self-esteem Scale of the California Psychological Inventory. The students had been told that the test was a personality inventory and was being administered to obtain information concerning the characteristics of Mississippi State students. They were told that they would receive their individual results in a few days.

\section{CURRENT LITERATURE ON SOCIAL PROCESSES}

ATWOOD, R. W. (Brigham Young University, Provo, Utah 84601), \& HOWELL, R. J. Pupillometric and personality test score differences of female aggressing pedophiliacs and normals. Psychonomic Science, 1971, 22, 115-116.

BLANK, E. P. (Johns Hopkins University, Baltimore, Md. 21218), \& ARENSON, S. J. Effects of previous order and proportion of similar attitude statements on attraction during a subsequent series of dissimilar statements. Psychonomic Science, 1971, 22, 245-246.

DUSTIN, D. S. (New York State University College, Plattsburgh, N.Y. 12901), \& ALFONSIN, B. Similarity and liking. Psychonomic Science, 1971, 22, 119.

JOHNSON, H. H. (Loyola University of Chicago, Chicago, nl. 60626), \& WATKINS, T. A. The effects of message repetitions on immediate and delayed attitude change. Psychonomic Science, 1971, 22, 101-103.

LA GAIPA, J. J. (University of Windsor, Windsor, Ontario, Canada), \& WERNER, R. E. Attraction and relevancy of attitude similarity-dissimilarity: Impersonal topics and friendship beliefs. Psychonomic Science, 1971, 22, 83-84.
LANE, I. M. (Louisiana State University, Baton Rouge, La. 70803), MESSE, L. A., \& PHILLIPS, J. L. Differential inputs as a determinant in the selection of a distributor of rewards. Psychonomic Science, 1971, 22, 228-229.

LINDSKOLD, S. (Ohio University, Athens, Ohio 45701), \& TEDESCHI, J. T. Reward power and attraction in interpersonal conflict. Psychonomic Science, $1971,22,211-213$.

MILLS, J. (University of Missouri, Columbia, Mo. 65201), \& O'NEAL, E. Anticipated choice, attention, and halo effect. Psychonomic Science, 1971, 22, 231-233.

MONTGOMERY, R. L. (University of Missouri, Rolla, Mo. 65401), \& ENZIE, R. F. Social influence and the estimation of time. Psychonomic Science, 1971, 22, 77-78.

ROUBERTOUX, P. (Institut d'esthétique et des sciences de l'art, University of Paris, 75-Paris, 5eme France), CARLIER, M., \& CHAGUibofF, J. Preference for non-objective art: Personal and psychosocial determiners. British Journal of Psychology, 1971, 62, 105-110.

SHAW, M. E. (University of Florida, Gainesville, Fla. 32601), \& BREED,
G. R. Some effects of attribution of responsibility upon the effectiveness of small problem-solving groups. Psychonomic Science, 1971, 22, 207-209.

SISTRUNK, F. (State University System of Florida, 107 West Gaines Street, Tallahassee, Fla. 2304). Interactions of source prestige, goal set, and task difficulty in conforming behavior. Psychonomic Science, 1971, 22, 109-111.

SMITH, R. E. (University of Washington, Seattle, Wash. 98105). Observational learning of modeled responses under shock-avoidance conditions as a function of attitude similarity and attraction toward the model. Psychonomic Science, 1971, $22,123-124$.

SUTTON, A. J. (School of Behavioural Sciences, Macquarie University, New South Wales, Australia). The use of quadratic discriminant analysis for the measurement of profile distance in social perception. British Journal of Psychology, $1971,62,253-260$.

WEISS, R. F. (University of Oklahoma, Norman, Okla. 73069), MILLER, F. G., LANGAN, C. J., \& CECIL, J. S. Social facilitation of attitude change. Psychonomic Science, 1971, 22, 113-114. 